support from: AbbVie, Genentech, Lilly, Novartis, Pfizer, Consultant for: AbbVie, Amgen, BMS, Genentech, Lilly, Regeneron, Sanofi, Pfizer DOI: 10.1136/annrheumdis-2019-eular.3082

\section{FRI0133 FILGOTINIB, A SELECTIVE JANUS KINASE 1 (JAK1) INHIBITOR, MODULATES DISEASE-ASSOCIATED CYTOKINES IN PATIENTS WITH ACTIVE RHEUMATOID ARTHRITIS}

Peter C. Taylor ${ }^{1}$, Emon Elboudwarej ${ }^{2}$, LI Wanying ${ }^{2}$, Rachael E. Hawtin ${ }^{2}$, Jinfeng Liu', Amer M. Mirza'. ${ }^{1}$ Botnar Research Centre, University of Oxford, Oxford, United Kingdom; ${ }^{2}$ Gilead Sciences, Inc., Foster City, United States of America

Background: Filgotinib (FIL), an oral selective JAK1 inhibitor, was safe and effective in FINCH2, a randomized, double-blind, placebo-controlled, phase 3 study in patients with active rheumatoid arthritis (RA) who had an inadequate response to biologic disease-modifying anti-rheumatic drugs (bDMARDs). ${ }^{1}$

Objectives: A longitudinal study of cytokines from patients in FINCH2 was conducted to identify RA-associated biomarkers related to bone biology, immune cell migration, and inflammation that are altered by FIL therapy; and FIL-associated biomarkers that correlated with clinical response (DAS28 [CRP], swollen and tender joint counts, pain, and fatigue).

Methods: Plasma, serum, and urine samples from RA patients $(n=449)$ who received FIL (100 mg, $200 \mathrm{mg}$ ) or placebo (PBO) once daily plus methotrexate were analyzed at baseline (BL) and week 12 for 42 disease-relevant cytokines using validated, commercially available single or multiplex assays. PBO-corrected on-treatment changes in cytokine levels from BL to week 12 were compared between treatment arms (Wilcoxon rank sum test). Spearman rank correlation was used to compare changes in cytokine level from BL to week 12 and clinical response. P-values $<0.05$ were considered significant.

Results: At week 12, 18 of 42 cytokines significantly decreased with FIL $100 \mathrm{mg}$ treatment relative to PBO; FIL $200 \mathrm{mg}$ decreased these cytokines to a similar or greater degree. An additional 6 cytokines were significantly decreased by FIL $200 \mathrm{mg}$. Conversely, 2 cytokines increased relative to PBO with FIL $100 \mathrm{mg}$, and 5 cytokines increased with FIL $200 \mathrm{mg}$ (sIL-6R, IL-10, IL-2, leptin, and IL-17A). Biomarkers most significantly modulated by FIL $200 \mathrm{mg}(\mathrm{p}<0.0001)$ included markers related to bone biology (MMP1 [-22.8\%], MMP3 [-24.7\%], CTX1 [-27.4\%], and NTX [-16.4\%]), immune cell migration (VCAM1 [-20.0\%], ICAM1 [$14.2 \%], \quad C X C L 13 \quad[-45.0 \%]$, and CXCL10 [-32.3\%]), and inflammation (TNFRI [-20.7\%], CRP $[-77.4 \%]$, SAA [-61.8\%], IL-6 [-13.6\%], and resistin $[-20.2 \%])$.

Hierarchical clustering of BL biomarker levels revealed distinct groups of cytokines that were strongly correlated with each other. Among them, SAA, IL-6, and CXCL10 were significantly positively correlated with each other (rho >0.6) and with RA disease activity (DAS28[CRP]) at BL (rho > 0.3). Biomarkers, including CRP (IL-6, SAA), PainVAS (CRP, SAA), and SJC28 (CRP, IL-6, CXCL10), were also significantly correlated with individual components of DAS28[CRP]. Several biomarkers associated with RA disease activity at BL were decreased with FIL at week 12 relative to PBO (FIL $100 \mathrm{mg}$ : CRP $[-48.7 \%]$, SAA $[-36.9 \%]$, and IL-6 $[-2.6 \%]$; and FIL $200 \mathrm{mg}$ : CRP [-77.4\%], SAA [-61.8\%], IL-6 [-13.6\%], and CXCL10 [-32.3\%]), suggesting FIL impacts these disease activities at a molecular level.

Conclusion: Twelve weeks of FIL treatment significantly reduced 24 disease-relevant cytokines associated with bone biology, immune cell migration, and inflammation in patients with active RA. These effects were dose-dependent and suggest a shift toward a restored immune homeostasis. These findings are consistent with the clinical efficacy of FIL in FINCH2.

\section{REFERENCES:}

[1] Genovese MC, et al. ACR 2018. Abstract L06.

Disclosure of Interests: Peter C. Taylor Grant/research support from: Celgene, Galapagos, Eli Lilly, UCB, Consultant for: AbbVie, Galapagos, Gilead, Eli Lilly, Pfizer Inc, Emon Elboudwarej Shareholder of: Gilead Sciences, Inc., Employee of: Gilead Sciences, Inc., Wanying Li Shareholder of: Gilead Sciences, Inc., Employee of: Gilead Sciences, Inc., MyoKardia, Rachael E. Hawtin Shareholder of: Gilead, Employee of: Gilead, Jinfeng Liu Shareholder of: Gilead Sciences, Inc., Roche, Employee of: Gilead Sciences, Inc., Amer M. Mirza Shareholder of: Gilead Sciences, Inc., Employee of: Gilead Sciences, Inc.

DOI: 10.1136/annrheumdis-2019-eular.2510

\section{FRI0134 \\ A PHASE 3 STUDY OF THE EFFICACY AND SAFETY OF PEFICITINIB (ASP015K) IN PATIENTS WITH RHEUMATOID ARTHRITIS WHO HAD AN INADEQUATE RESPONSE TO DMARDS}

Yoshiya Tanaka ${ }^{1}$, Tsutomu Takeuchi ${ }^{2}$, Sakae Tanaka ${ }^{3}$, Atsushi Kawakami ${ }^{4}$, Manabu Iwasaki ${ }^{5}$, Yeong Wook Song ${ }^{6}$, Yi-Hsing Chen ${ }^{7}$, Mitsuhiro Rokuda ${ }^{8}$, Hiroyuki Izutsu $^{8}$, Satoshi Ushijima ${ }^{8}$, Yuichiro Kaneko ${ }^{8}$, Teruaki Shiomi ${ }^{8}$,

Emi Yamada ${ }^{8}{ }^{1}$ University of Occupational and Environmental Health, Kitakyushu, Japan; ${ }^{2}$ Keio University, Tokyo, Japan; ${ }^{3}$ University of Tokyo, Tokyo, Japan; ${ }^{4}$ Nagasaki University, Nagasaki, Japan; ${ }^{5}$ Yokohama City University, Yokohama, Japan; ${ }^{6}$ Seoul National University Hospital, Seoul, Korea, Rep. of (South Korea);

${ }^{7}$ Taichung Veterans General Hospital, Taichung City, Taiwan, Republic of China;

${ }^{8}$ Astellas Pharma, Inc., Tokyo, Japan

Background: Peficitinib (ASP015K), a novel oral JAK inhibitor, demonstrated efficacy as once-daily monotherapy in patients with moderate to severe rheumatoid arthritis (RA) in a phase 2b study (NCT01649999). Objectives: To evaluate the efficacy and safety of peficitinib alone or in combination with disease-modifying antirheumatic drugs (DMARDs) in patients with RA who had an inadequate response to DMARDs.

Table 1 Primary and selected secondary efficacy endpoints at week 12/ET

\begin{tabular}{|c|c|c|c|c|}
\hline $\begin{array}{l}\text { Result at week } \\
\text { 12/ET }\end{array}$ & PBO & $\begin{array}{l}\text { Peficitinib } \\
100 \mathrm{mg} / \text { day }\end{array}$ & $\begin{array}{l}\text { Peficitinib } \\
150 \mathrm{mg} / \text { day }\end{array}$ & \begin{tabular}{|l} 
Etanercept \\
$50 \mathrm{mg} /$ week \\
(open-label arm)
\end{tabular} \\
\hline ACR20 $0^{\circ}, \mathrm{n} / \mathrm{N}(\%)$ & $31 / 101(30.7)$ & $60 / 104(57.7)^{* * *}$ & $76 / 102(74.5)^{* * * *}$ & $167 / 200(83.5)$ \\
\hline$A C R 50^{\circ}, \mathrm{n} / \mathrm{N}(\%)$ & 9/101 (8.9) & $32 / 104(30.8)^{* * *}$ & $43 / 102(42.2)^{* * *}$ & $105 / 200(52.5)$ \\
\hline ACR70 $70^{\circ}, n / N(\%)$ & $1 / 101(1.0)$ & \begin{tabular}{|l|}
$14 / 104(13.5)^{b, c}$ \\
\end{tabular} & $28 / 102(27.5)^{* * * *}$ & $61 / 200(30.5)$ \\
\hline $\begin{array}{l}\text { Mean (SD) CRP } \\
\text { change from } \\
\text { baseline, } \mathrm{mg} / \mathrm{dL}\end{array}$ & $0.022(1.498)$ & $-1.056(1.908)^{* * * *}$ & $-1.734(1.906)^{* * *}$ & $-1.207(2.694)$ \\
\hline $\begin{array}{l}\text { Mean (SD) ESR } \\
\text { change from } \\
\text { baseline, } \mathrm{mm} / \mathrm{h}\end{array}$ & $-1.96(17.82)$ & $-12.96(21.51)^{* * *}$ & $-23.92(21.26)^{* * *}$ & $-20.92(21.66)$ \\
\hline $\begin{array}{l}\text { DAS28-CRP }<2.6^{a}, \\
\mathrm{n} / \mathrm{N}(\%)\end{array}$ & $5 / 100(5.0)$ & $25 / 102(24.5)^{* * *}$ & $35 / 101(34.7)^{* * *}$ & $91 / 200(45.5)$ \\
\hline $\begin{array}{l}\text { Mean (SD) DAS28- } \\
\text { CRP change from } \\
\text { baseline }\end{array}$ & $-0.64(1.20)$ & $-1.62(1.41)^{* * *}$ & $-2.17(1.14)^{* * *}$ & $-2.42(1.11)$ \\
\hline $\begin{array}{l}\text { Mean (SD) change } \\
\text { from baseline in } \\
\text { patient's assessment } \\
\text { of pain, } 100 \mathrm{~mm} \text { VAS }\end{array}$ & $-6.64(24.61)$ & $-23.78(30.75)^{* * *}$ & $-30.65(27.91)^{* * *}$ & $-30.82(27.68)$ \\
\hline \begin{tabular}{l|} 
SDAl remission \\
(SDAl score $\leq 3.3)^{\mathrm{a}}$ \\
$\mathrm{n} / \mathrm{N}(\%)$
\end{tabular} & $0 / 100(0.0)$ & $9 / 102(8.8)^{b}$ & $9 / 101(8.9)^{b}$ & $37 / 200(18.5)$ \\
\hline \multicolumn{5}{|c|}{ 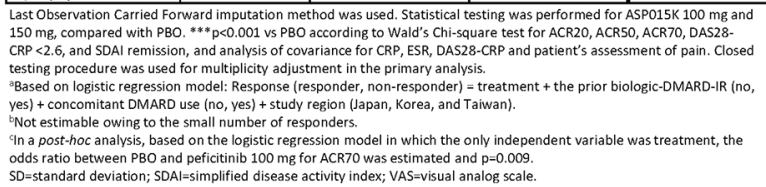 } \\
\hline
\end{tabular}

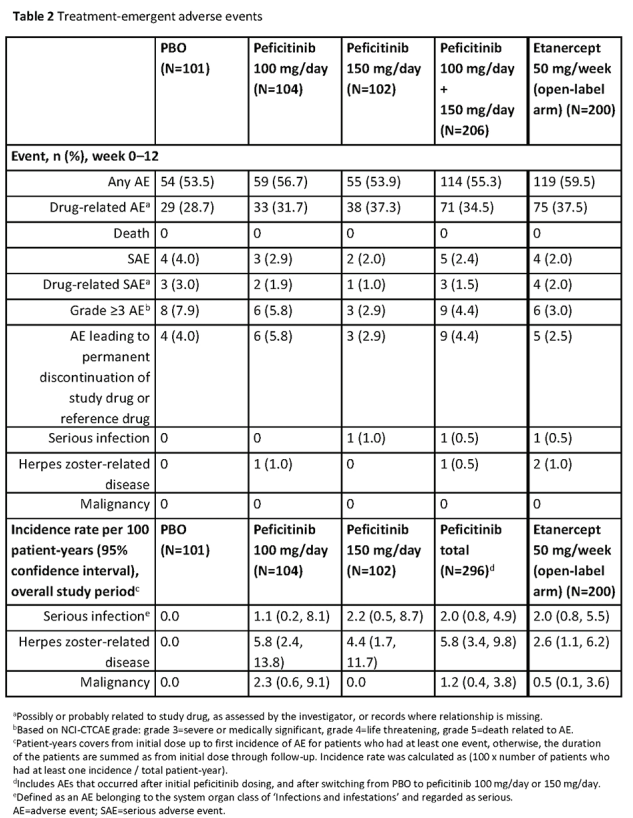

